\title{
MARIO CASTELNUOVO-TEDESCO (PRESENCIA TOSCANA EN LA MÚSICA)
}

JORGE VELAzCo

Es posible que no exista manera de apreciar, e incluso enfocar, correctamente a un compositor muy cercano en el tiempo. La historia está repleta de autores que fueron famosos y respetados en sus días y cuya obra se ha desvanecido de la memoria y la tradición. Otros hay que fueron ignorados en su tiempo y que llegaron después a la cumbre de la gloria, eI reconocimiento $\mathrm{y}$ la difusión de su pensamiento musical en el mundo entero. Las opiniones de sus contemporáneos en uno y en otro sentido, provienen de toda clase de autoridades, desde el crítico ignorante y el aficionado entusiasta e iletrado, hasta los profesionales del más alto entrenamiento $e$ incluso los grandes genios creadores de la humanidad, esos que pasaron a la historia y que juzgaron a otros como ineptos o como gigantes, errando por completo en sus puntos de vista relacionados con sus colegas.

Todo esto viene a cuento por la proximidad de Mario CastelnuovoTedesco a nuestra época y la probable imposibilidad de emitir una evaluación certera de su estatura. Después de todo, ha habido muchos compositores geniales, cuyas posibilidades de comunicación colectiva no han sido tan fluidas y directas como las de Bach o Beethoven, pero que permanecen en lo que podríamos llamar el legado histórico de la música.

Pero hay otros autores cuya obra se ha eclipsado por completo de la vista de quien no es historiador, pese a su pasada celebridad o a su auténtico papel como base artística y fundamento musical de obras capitales en la historia de la música, que permanecen como pilares inconmovibles (al menos en nuestra época) del repertorio conocido. Siempre me ha divertido profundamente contemplar el desconcierto de los críticos ignorantes cuando escuchan por primera vez la música de cualquiera de los antecesores de Mozart o Beethoven, gritan que se trata de plagios estilísticos y luego se dislocan la quijada ante la "revelación" (para ellos) de que si alguien plagió fue su adorada cumbre, que siempre imaginaron -dado su desconocimiento- como una especie de fenómeno divino, aislado e independiente del desarrollo cultural y social de la humanidad.

No sabría decir cuál será el destino de la obra de Castelnuovo-Tedesco ni cuál fue su caso como creador de música. Artistas de la eminencia histórica y profesional de Andrés Segovia lo respetan con un fervor que 
necesariamente debe hacer vacilar cualquier juicio improvisado, tanto positivo como negativo. Diversos investigadores lo aclaman como un miniaturista genial, capaz de dar vida sonora a las evocaciones impresionistas más delicadas e intensas que se pueda concebir. Otros hay que le reprochan su falta de dramatismo y su escaso vigor épico, basados en la idea de que un autor de música debe tender necesariamente a las profundidades conceptuales o emocionales de un Berlioz, de un Chaikorski o de un Mahler, y llegan a encontrar un parámetro de juicio negativo contra el compositor decretando el fracaso de su obra madura y global en relación con sus primeras piezas, mediante la teoría de que sus creaciones juveniles parecían predecir la existencia de un talento dramático capaz de expresarse en formas largas y grandiosas. En el fondo, lo que hacen es reprochar a Chopin al carecer de la dimensión emocional de un Verdi, toda excepción admitida en cuanto al genio de ambos autores y la proporción de la metáiora en relación con Castelnuovo-Tedesco.

El resumen es que no podemos explicar completamente, ni evaluar en su totalidad, ni predecir el desarrollo de la popularidad de la obra de Castelnuovo-Tedesco, gracias a su cercanía historica con el momento presente. Lo que sí podemos es afirmar que el fenómeno estético representado por su creación es de una magnitud extraordinaria que nos enfrenta con la necesidad de respetarlo y la obligación de difundir su obra para que el desarrollo artístico y cultural futuro defina su posición como comunicador, ya que su valor estético intrínseco sólo puede ser captado por quienes teniendo el conocimiento y la experiencia, dediquen largos años àl estudio del resultado de su actividad creadora.

La primera dificultad para tratar el tema de Castelnuovo-Tedesco, por superficial y leve que sea el intento, radica en la enorme extensión de su obra, que comprende más de doscientos números de opus, y en el hecho de que una gran cantidad de sus piezas no han sido publicadas hasta la fecha. Es cierto que en los siglos xvir y xvir la obra integral de gran extensión fue muy común. Tanto Telemann como Hændel, Bach, Mozart e incluso Schubert tienen alrededor de mil obras cada uno en sus catálogos, pero en esas épocas (y corrientes artísticas) los elementos formulares en la composición musical eran un tanto más sencillos y se aceptaban con menores reparos que en el siglo $\mathrm{xx}$, cuando las fórmulas de composición se han complicado mucho (en parte gracias a Mahler y Stravinski) y se ha hecho un punto clave de la originalidad para cada obra, del valor de la diversidad en cada pieza y del énfasis en evitar la repetición de fórmulas e instituciones musicales, por to 
menos en cuanto a su posibilidad de captación inmediata, ya que todavia no he oído protestas estéticas por el hecho de que Mahler utilizó el mismo y el único material temático en toda su obra, que reiteró al infinito usando los mismos moldes armónicos y las mismas fórmulas estructurales, al igual que Bach y que Hændel.

En relación con Castelnuovo-Tedesco, el asunto tiene otro cariz. Las mil repeticiones de Mozart pasan un tanto inadvertidas por el hecho de que la gran mayoría de su obra no es conocida por el público general. En el caso del compositor ítalo-norteamericano, la impasibilidad de repetir el esquema profesional del barroco nos enfrenta a un fenómeno de originalidad muy escasamente visto en la historia. Castelnuovo-Tedesco fue uno de los creadores más prolificos de la era moderna y si ello hace prácticamente imposible su valuación en el momento actual, también apunta la presencia de un talento creador de primera línea, que cualesquiera que hayan sido sus medios y alcances expresivos, tiene la dimensión hipotética de un gran compositor, de aquellos que pueden permanecer en el oído del público y la mente del profesional por largo tiempo. Lo necesario, imprescindible, será que su obra completa sea editada, grabada, divulgada en toda la extensión de Ia palabra.

Mario Castelnuovo-Tedesco nació en Florencia, Italia, el 3 de abril de 1895 . Entre 1913 y 1918 estudió en el Real Instituto Cherubini de su prodigiosa ciudad natal. En ese conservatorio fue alumno de composición de Ildebrando Pizzetti (1880-1968) y de piano de Edgardo del Valle de Paz (1861-1920), entonces famoso pianista, compositor y escritor de asuntos musicales. En 1914 obtuvo el diploma de piano, y en 1918 el de composición. Poco antes de recibir su diploma de composición conoció a Alfredo Casella (1883-1947), quien se ocupó entusiastamente de promover la música del joven autor en Italia, a través de la Sociedad Italiana de Música Moderna, y en el resto del mundo, a través de sus muchos y poderosos contactos.

Así es que, antes de los veinticinco años y sin haber compuesto (al contrario de Shostakovich y Prokofiev) ninguna sinfonia, CastelnuovoTedesco se estableció como compositor famoso en Florencia, tocando esporádicamente el piano en público. Su facilidad para componer fue asombrosa. Historias similares a las que se cuentan de Saint-Saëns, capaz de componer una obra mientras dialogaba en una fiesta con unos amigos y mandarla sin más a la imprenta, se cuentan de Castelnuovo-Tedesco. El olvidado arte de la improvisación pareció florecer de nuevo en sus manos, incluso tocó varias veces en público improvisaciones muy com- 
plejas que no aprovechó después. Su vena melódica y creadora parecía inagotable y de suyo le acompañó a lo largo de toda su vida.

En Florencia, disfrutaba de la inefable dicha y felicidad de la vida en Italia y el perfume secular (histórico y de sabiduría vital) de la pragmática existencia toscana, que alimentó y señaló de modo decisivo, definitivo y determinante toda su obra. La influencia del cielo y el paisaje rural toscano, la vieja y calmada cultura de la sabia pero senilmente frivola sociedad fiorentina y su amor por Shakeaspeare fueron los condicionantes capitales de su vida y obra creativa. En 1939, el paraíso se cerró y Castelnuovo-Tedesco hubo de emigrar a los Estados Unidos, ante la amenaza de que el fascismo le hiciera lo que a tantas personas se les hizo en virtud de su raza o religión. Se estableció primero en Larchmont, Nueva York, pero en 1940 se cambió a Beverly Hills, California, donde se ganaba la vida componiendo música para películas, ocupación que desarrolló sistemáticamente durante algo más de quince años, un poco a la manera de los primeros años mexicanos de Rodolfo Halffter. En 1942 ingresó al Conservatorio de Los Ángeles como profesor de composición y en 1946 adquirió la nacionalidad norteamericana.

Quien ha probado el dulce veneno de Italia, sucumbe sin remedio al serento encanto y la tranquila vitalidad de aquella hermosa vida social y Castelnuovo-Tedesco regresó a Toscana cada verano que le fue posible después de la guerra, situación tal vez inevitable una vez que se ha degustado la enriquecedora y plena vida italiana. Cuando murió, el 16 de mayo de 1968, había escrito -además de sus numerosas composicionesvarios artículos y una autobiografía que sigue inédita, Una vita di mussica.

La obra de Castelnuovo-Tedesco es consistente y acorde con su cultura y con sus aficiones artísticas fuera del área de la música. La constante presencia del impulso emotivo derivado de Toscana y basado en sus impresiones paisajísticas y sociológicas, junto con el énfasis que el compositor puso siempre en Shakespeare, nos hablan muy claramente de sus intereses y sus fuentes de inspiración. No deja de ser triste, a pesar de ser natural, que de un autor tan prolífico se conozcan sólo unas cuantas obras y qüe una gran cantidad de su música no se haya publicado todavía. Mucho de lo que se admira de Castelnuovo-Tedesco fue compuesto àntes de 1940 y el mismo compositor señalaba como definitivas y muy importantes diversas obras de su periodo norteamericano que permanecen inéditas. Castelnuovo-Tedesco fue un compositor que definió la mayor parte de su estilo y lenguaje armónico y rítmico desde muy joven (al igual que Prokofiev), que ya no indujo variación alguna en sus prin- 
cipios musicales básicos y se contentó con expresarlos y explotarlos durante el resto de su vida, hasta sus últimas consecuencias, pero siempre en el camino trazado, sin perder de vista su punto de partida. Tuvo la ventaja (de la que no disfrutó Prokofiev) de no tener que variar su estilo para complacer las órdenes de ningún músico frustrado investido de autoxidad gubernamental casi absoluta.

Castelnuovo-Tedesco cultivó siempre un impresionismo parco, de un carácter estético y estilístico similar al de Falla, si bien el italiano careció de la tremenda fuerza creadora del genial español y no tuvo como habitat musical un folklore tan rico y tan espeso como el que había en España antes de la gran comercialización gitana que siguió a la Guerra Civil.

Los primeros años creativos de Castelnuovo-Tedesco tuvieron bastante relación con el piano, instrumento en el que pudo expresar su novedoso tipo de impresionismo, su refinada y elegante sensibilidad, su intensa musicalidad, sus originales métodos armónicos y rítmicos y su meticuloso cuidado y atención a los detalles sutiles y al perfecto acabado artesanal de sus piezas. Magníficos ejemplos de lo arriba mencionado son Cielo di settembre, Op. 1 (1910); Lucertolina (1916); Questo fu il carro della morte, Op. 2 (1913); las tres Piezas marinas: El rayo verde, Op. 9 (1916); Algas, Op. 12 (1919) y Los navegantes, Op. 13 (1919); Cipreses, Op. 17 (1920) y La sivenita y el pez turco, Op. 18 (1920). Incluso una de estas refinadas obras, Questo fu il carro della morte, hija de la estética de Brueghel el Viejo, ha engañado a más de un crítico, de esos que confunden las miniaturas flamencas de madera con las esculturas de Miguel Ángel, que le adjudican una intención dramática que no tiene, ya que su impacto deriva más del abigarrado nivel de fantasmagoría de Bosch que de las titánicas y aterradoras figuras de un Goya. Hil ampiio catálogo pianístico de Castelnuovo-Tedesco incluye alrededor de sesenta obras, algunas integradas por piezas múltiples, que delinean muy claramente su estética. A Tres poemas campestres, Op. 44 (1926) se contraponen Tres preludios alpinos, $O p .84$ (1935). Al menos tres obras largas, con su característico estilo rapsódico de improvisación meditada, tienen claros y reconocibles temas populares y tradicionales: Alt Wien, $O p .30$ (1923); Piedigrota 1924, Op. 32 (1924) y Las danzas del rey David, Op. 37. (1925). Por lo demás, hay una Fantasia y fuga sobre el nombre de Ildelbrando Pizzetti, Op. 63 (1930); Pasatiempos, Op. 54 (1928); Veintiocho piezas cortas (1949) y la Sonatina Zoológica, Op. 187 (1960), prueba máxima de la incréble coherencia de su unidad estilística, pues utiliza como segundo movimiento a Lucertolina de 1916, sin que pueda detec- 
tarse ninguna brecha entre esa pieza compuesta cuarenta y cuatro años antes y el resto de la obra.

Castelnuovo-Tedesco tuvo la natural atracción por la escena que todos los compositores italianos parecen sentir. En su caso, ese gusto se vio aumentado por su pasión por Shakespeare y la literatura inglesa, que le llevó a diversas empresas en el curso de su vida creadora. En 1926, se estrenó en Venecia La Mandrágora, $O p$. 20, sobre un texto de Maquiavelo, que se repitió en Wiesbaden dos años después, si bien en una versión acortada que redujo a dos actos el original tríptico de la obra. Al otro extremo temporal de su ciclo creador nos hallamos dos óperas basadas en Shakespeare: El Mercader de Venecia, Op. 181 (1956), representada en Florencia en 1961 y A buen fin no hay mal principio, $O p$. 182. Saul, Op. 191, sobre texto de Alfieri, fue concluida en 1960 y en 1962 terminó una ópera de cámara sobre el retruécano de Wilde, The Importance of Being Earnest (ocho voces, dos pianos y percusionn), que fue estrenada por la RAI en 1972.

Hubo, además, varios ballets, música incidental para diversas obras (entre las que destacan las de Pirandello - Los gigantes de la montañay Allessi-Savonarola); unas veinte partituras para películas, El Cantar de los Cantares, Op. 172 (subtitulado "idilio rústico de esponsales"), estrenada en Hollywood en 1963 y una "fábula para marionetas", Aucassin et Nicolette, sobre el tema medieval francés correspondiente, escrita en 1938, antes de abandonar Italia, y estrenada en Florencia en 1952.

Tal rez la más importante e interesante obra escénica de CastelnuovoTedesco es el ballet Baco en Toscana, Op. 39, naturalmente basado en Redi, compuesto entre 1925 y 1926 y estrenado en Milán en 1931. Tiene dos voces solistas, coro y orquesta y es imposible concebir a un autor capaz de emprenderla con ese chispeante poema de Redi sin estar irrevocablemente comprometido con todas las esencias de la vida toscana y la cultura italiana. El elogio del vino que bulle en esas líneas no es la apología del alcoholismo sino el comentario entusiasta de la vida $y$ la comida en aquella tierra de sol, ondulantes colinas, cipreses, viñedos, cielo de luminoso azul, frondosos árboles llenos de pájaros, ciudades sin par y la constante presencia de la historia, que parece venir a nosotros en el puro aire que allá se respira y que carga de sabiduría las más elementales funciones de la vida cotidiana.

En sus canciones, Castelnuovo-Tedesco escala nuevas y grandes alturas de originalidad y espectro expresivo, bien expuestas en marcos rítmicos 
y armónicos de novedosa creación. La extensión literaria de sus textos es de lo más interesante: Le roi Loys, Op. 3 (1914), con texto medieval francés; Estrellas fugaces, Op. 6 (1915-1918), sobre textos tradicionales toscanos; Coplas, $O p .7$, con textos tradicionales españoles; El infinito, Op. 22 (1921), con texto de Leopardi; Treinta y tres canciones de Shakespeare, Op. 24 (1921-1928); Nueve canciones de Heine, Op. 40 (1926) y Op. 46 (1929); Ocho bromas para música, Op. 35 (1924-1925), con texto de Redi; Cuatro sonetos de "La Vida Nueva", Op. 41 (1926); Seis Odas de Horacio, Op. 62 (1930); La Balada de los bienes inmue. bles, Op. 68 (1931), de Gide el tríptico Louisiana, Leaves of Grass, Ocean, Op. 81 (1936), con texto de Whitman; Tres fragmentos de Marcel Proust, Op. 88 (1936); Veintiséis sonetos de Shakespeare, Op. 125 (19441947); Cuatro sonetos de Shakespeare (1963); Dos liricas de "El Jardinero" (1917), de Tagore; Tres florecillas de San Francisco, Op. 11 (1919-1920); Seis Canciones Escocesas, Op. 100 (1939) con texto de Scott; El Arca de Noé (1944), compuesta para la obra colectiva Suite Génesis, en la que los más destacados colaboradores fueron Stravinski y Schönberg; La noche de Fiesole (1923), con texto de d'Annunzio; Dos baladas de Schiller, Op. 193 (1961), para narrador, dos pianos y percusiones; Tres duetos de Shakespeare, Op. 97 (1937) y cerca de cien obras más, tanto para voz solista como para diversas combinaciones y coro, que no mencionaré, entre los que hay textos de Walther von dex Vogelwaide, Cavalcanti, García Lorca, Esquilo y Virgilio.

La obra de cámara de Castelnuovo-Tedesco, que incluye docenas de piezas para todo tipo de combinaciones, es la más inexplorada hasta este momento. Hay obras para dos instrumentos (violoncello y piano, violín y piano, violín y viola, clarinete y piano, fagot y piano, viola y violoncello, violín y violoncello, trompeta y piano, flauta y guitarra, violoncello y arpa, guitarra y piano, viola y piano), además de obras para órgano arpa, cuartetos, quintetos, sextetos y diversas combinaciones entre tres y nueve instrumentos. Su música de cámara es el área más rapsódica de su producción, pero a la vez resulta de una solidez instrumental verdaderamente notable. Tal vez algún día los músicos la descubrirán.

En el campo de la música oxquestal, Castelnuovo-Tedesco dio rienda suelta a su gusto por Shakespeare, componiendo diversas oberturas para sus obras: La fierecilla domada, Op. 61 (1930); Noche de Epifania, Op. 73 (1933); El mercader de Venecia, Op. 76 (1939); Julio César, Op. 78 (1934); Cuento de invierno, Op. 80 (1934); Un sueño de una noche de verano, Op. 108 (1940); El Rey Juan, Op. 111 (1941); Antonio y 
Cleopatra, Op. 134 (1947); La tragedia de Coriolano, Op. 135 (1947); Mucho ruido y pocas nueces, Op. 164 (1953); Como gustéis, Op. 166 (1953) ; además de cuatro danzas para Trabajos de amor perdidos, $O p$. 167 (1959). Estas obras son la parte mas chispeante, bulliciosa, elegante y lograda de sus trabajos para orquesta, si bien los conciertos para diversos instrumentos podrían tener una mayor profundidad musical. En ese terreno hay dos conciertos de piano (Op. 46, 1927; Op. 92, 1936-1937), uno de oboe (Op. 146, 1950), dos de guitarra (Op. 99, 1939; Op. 160, 1953), dos piezas concertantes para guitarra (Serenata, Op. 118, 1943 y Capricho diabólico, Op. 85b, 1945, basado en la obra para guitarra sola del mismo nombre), uno para dos guitarras $(O p$. 201, 1962), tres para violín ("Italiano", Op. 31. 1924; "Los profetas", Op. 66, 1931; Op. 102, 1939), dos piezas concertantes para violín (Variaciones sinfónicas, Op. 118, 1928; el Poema "Larchmont Woods", Op. $112,1942)$, uno para violoncello y una pieza concertante para el mismo instrumento (Los noctámbulos, arreglo hecho en 1960 de una obra para cello y piano del mismo nombre - Op. 47- compuesta en 1927). Las otras obras orquestales tienen la característica temática de Castelnuovo-Tedesco, entre ingenua y sincera, llena de evocaciones simples de muy cuidadoso acabado: El cumpleaños de la Infanta, Op. 115 (1942); Canciones y danzas indias, Op. 116 (1942), Cinco humorescas, Op. 121 (sobre temas de Foster-1943) y la inevitable Rapsodia Americana (1943) de todo compositor extranjero asimilado al medio nacional de los Estados Unidos antes de la era atómica. Otras obras para orquesta de Mario Castelnuovo-Tedesco son transformaciones de diversas piezas. La orquestación de obras concebidas para otros medios fue muy usual en este compositor. Cielo di settembre fue orquestado en 1915, Cipreses, en 1921, con una revisión en 1939, Le Roi Loys en 1930, Coplas en 1967, La balada de los bienes inmuebles en 1934, Tres duetos de Shakespeare en 1938, incluso La sirenita y el pez turco se transformó en el ballet Pesce turchino, estrenado en Florencia en 1937.

Además de su gusto por el folklore musical español. Mario Castelnuovo-Tedesco se interesó profundamente en el canto litúrgico judío. En ese campo, y como natural consecuencia de la confluencia de sus intereses y nacionalidad, Castelnuovo-Tedesco siguió la tradición sefardita del sur de Francia, España y algunas áreas del Oriente medio. Un tanto a la manera de Milhaud, compuso una diversidad de obras con claras relaciones bíblicas o pertenecientes a una intención litúrgica del rito sefardita. Tenemos Tres corales sobre melodias hebreas, Op. 
43 (1926) para piano; el oratorio escénico Tobias y el ángel, Op. 204 (1964-1965), estrenada en Nueva York en 1975 y emparentada con las ideas originadas por Anton Rubinstein en ese campo; y una larga serie de obras corales, entre las que destacan varios oratorios (El libro de Ruth, Op. 140, 1949; El libro de Judith, Op. 151, 1951; El libro de Esther, Op. 200, 1962) y una buena cantidad de piezas para coro con diversos intrumentos: Kolnidrei (1944); Ruth y Noemi, Op. 137 (1947); La reina de Saba, Op. 161 (1953); El horno fiero, Op. 183 (un Bar escrito en 1958); Servicio en memoria de los desaparecidos, Op. (1960); Servicio sagrado, Op. 122 (Bar de 1943) y Naaritz'cho (1952).

La confluencia del rito sefardita, España y Andrés Segovia, le dio a Castelnuovo-Tedesco la más importante de sus dimensiones como compositor, ya que su obra para guitarra, alentada y supervisada por el gran Segovia, se ha convertido en la parte más respetada, difundida y gustada de su obra. Tal vez la más importante de todas es el Concierto, en Re mayor, Op. 99, probablemente la más original y bella obra para guitarra y orquesta que existe.

El autor escribió sobre su concierto:

Quizá nunca habría escrito para la guitarra de no ser por Andrés Segovia, ese maravilloso artista y fiel amigo. Fue a petición suya que compuse el Concierto, en Re mayor, para guitarra y orquesta que él estyenó en Montevideo, en octubre de 1939. Fue la última obra que compuse en Italia, antes de emigrar a los Estados Unidos y, curiosamente, a pesar de haberla escrito en el periodo más trágico de mi vida, es una de las más serenas, su construcción sigue el usual esquema de los tres movimientos. El primero, un allegro, podxía ser considerado como "neoclásico", está cercano al estilo de Boccherini (como las primeras sonatas). El segunido movimiento tiene rasgos románticos en su tierno adiós a la campiña toscana que estaba a punto de abandonar. El tercer movimiento, español por temperamento, es audaz y de gran pulso rítmico, en el espiritu de las antiguas baladas. Los tres movimientos tienen grandes cadencias para el solista.

Este contemporáneo del Concierto de Aranjuez, menos famoso que el español es, sin embargo, una de las más acabadás obras (si no la más) del repertorio guitarrístico y uno de los más finos de todo el repertorio concertante. Su capacidad, casi fantasmal, para evocar estados de ánimo, recuerdos de cosas que no se vivieron, ecos de voces que no se conocieron, es asombroso. Tal vez nadie, ni el mismo CastelnuovoTedesco, ha escrito otra obra para guitarra que sea tan perfecta en cuanto al equilibrio entre la técnica y la expresión. 
Esta obra no fue sino una de las tantas instancias en las que la estimulante labor de Andrés Segovia llevó al compositor al conocimiento de un mundo nuevo, inexploxado y sutil, que podxía proveerle de los medios y ambientes expresivos que su evocadora fantasía, llena de nostalgia por los fantasmas del pasado toscano, sombras del mundo romano, buscaba constantemente.

El catálogo de obras para guitarra es el más interesante de los autores del siglo $\mathrm{xx}$ y, otra vez, refleja al mundo toscano (esta vez con un toque ibérico) muy intensamente: Variaciones a través de los siglos, $O p .71$ (1932); Sonata, Op. 77 (1934); Tarantella y Naranjos en flor, Op. 87 (1936); Variaciones gentiles sobre un pequeño aire popular, Op. 95 (1937); Rondo, Op. 124 (1946); Suite, Op. 133 (1947); Tres preludios mediterráneos, Op. 176 (1955); La guarda cuydadosa y Escarramán, Op. 177 (1955), sobre temas literarios de Cervantes; Pasacalle, Op. 180 (1956) tres volúmenes de Apuntes, Op. 210 (1967-1968); Platero y yo, Op. 190 (1960), para narrador y guitarra, con texto de Juan Ramón Jiménez; Veinticuatro caprichos de Goya, Op. 195 (1961); Sonatina canónica. Op. 196 (1961), para dos guitarras; Las guitarras bien temperadas, Op. 199 (1962), para dos guitarras; Fuga elegiaca (1967), para dos guitarras, además de veinte números en la serie que sigue al opus 170 y varias canciones para voz y guitarra, entre las que destaca, desde el punto de vista de caracterizar su obra, El diván de Moisés ibn Ezra, Op. 207 (1966).

Mario Castelnuovo-Tedesco es un compositor difícil de comprender. Por una parte, su espíritu neoclásico y conservador enajena la voluntad de las mentes musicales de avanzada estética cuando su corazón no es sincero y su cerebro tiene impedimentos emocionales, e irrita francamente a los farsantes de la música contemporánea, quienes se rasgan las vestiduras, a fuer de sacerdotes de la vanguardia, cuando tienen que confrontaxse con un autor pulido, de técnica perfecta y totalmente desinteresado en épater le bourgois. Por otra, las almas conservadoras, usualmente ligadas emotivamente a la concepción grandiosa y monumental de la música, tienden a despreciar a un autor que no se preocupó jamás por elaborar El oro del Arno y capaz de cantar las glorias del vino toscano. Un tercer ángulo del público extraña la falta de intensidad dramática de Castelnuovo-Tedesco, olvidando que Verdi ha sido un fenómeno único en al historia.

Pero la creación artística produce un resultado muy objetivo, con existencia propia, contundente y mensurable en cuanto a su extensión y vitalidad, similar a las fuerzas o las cosas de la naturaleza. Las obras 
están ahí, nos gusten o no, y no han sido hechas para complacernos, nos guste o no. Así es que la obra de Mario Castelnuovo-Tedesco está ahí, bien hecha y abundante, proveniente de un autor que tenía una capacidad melódica e improvisatoria extraordinaria, un conocimiento técnico profundísimo, una sabiduría vital muy grande y una generosa bondad de corazón. Su obra puede ser ofensiva para los pedantes, puede ser trivial para los petulantes, puede ser superficial para las almas aficionadas a las palabrotas filosóficas, puede ser idealizada por los guitarristas, puede ser respetada por los amantes de las evocaciones nostálgicas. Todo ello no tiene la menor importancia, lo que importa es que allí está, le agrade o no a los críticos. 